\title{
Contextual Factors in the Open Approach-Based Mathematics Classroom Affecting Development of Students’ Metacognitive Strategies
}

\author{
Ariya Suriyon ${ }^{1}$, Maitree Inprasitha ${ }^{2}$, Kiat Sangaroon ${ }^{3}$ \\ ${ }^{1}$ Department Doctoral Program in Mathematics Education, Khon Kaen University, Khon Kaen, Thailand \\ ${ }^{2}$ Center for Research in Mathematics Education, Khon Kaen University, Khon Kaen, Thailand \\ ${ }^{3}$ Department of Mathematics, Faculty of Science, Khon Kaen University, Khon Kaen, Thailand \\ Email: ariya.su@hotmail.com
}

Received July $8^{\text {th }}$, 2013; revised August $16^{\text {th }}$, 2013; accepted August $29^{\text {th }}, 2013$

Copyright (C) 2013 Ariya Suriyon et al. This is an open access article distributed under the Creative Commons Attribution License, which permits unrestricted use, distribution, and reproduction in any medium, provided the original work is properly cited.

\begin{abstract}
The objective of this research was to study the effect that contextual factors have on the development of students' metacognitive strategies in the open approach-based mathematics classroom: the framework for learning and teaching activities in the class, the teacher's role, and students' role. The methodology was based on ethnographic research and Begle's conceptual framework (1969), which focused on observation and study on the nature of occurrences. In the context, the researcher conducted participatory classroom observation. The target groups were a mathematics teacher, who is a student as a math teaching practitioner, and four elementary school students at Grade 1 ranging from 6 to 7 years of age from Koo Kham Pittayasan School. Data were collected from 3 learning units totaling 6 study periods. Qualitative data analysis procedures were based on analyzing videos, protocols, students' written work, and time units for dealing with activities and narrative description. The concept of 4 open approach-based teaching steps (Inprasitha, 2010) was considered for the analysis of the teacher's teaching behavior and students' problem solving behavior. The study findings suggest that contextual factors in the open approach-based mathematics classroom affect the development of students' metacognitive strategies in which the teacher has planned learning management related to learning unit structures and focused on instructional activities allowing students "to create knowledge from learning how to solve problems by themselves". In addition, the study demonstrates that the teacher and students have different roles in each teaching step.
\end{abstract}

Keywords: Contextual Factors; Metacognitive Strategies; Lesson Study; Open Approach

\section{Introduction}

A review of research papers on mathematical problem solving with regard to metacognition yields findings that fall under the fundamental concept of Flavell (1976) regarding monitoring and regulation. The importance of research into the teaching of problem solving has been acknowledged since the 1980s (Lester, 1994), the researchers attempted to find explanations for various aspects due to the belief that metacogntion is what makes a problem solver successful in solving problems, corresponding to Lesh (1982), Silver (1982) and Schoenfeld (1982) showing that metacognitive actions as "a driving force" in problem solving.

Use of metacogntive strategies is considered a strategy that a problem solver applies to solving problems with various aims besides that of finding answers only. In other words, it is a strategy that a problem solver uses to monitor his or her goal in problem solving, or it can be said that he or she is a problem solver with characteristics of good thinking. Monitoring as mentioned above can be seen from monitoring behavior and reflection on a problem solver's thinking process from work which he or she has already done. As for arranging learning and teach- ing activities in a class to stimulate or prompt students to apply metacognitive strategies, it is considered difficult and complicated. Allowing students to have a chance to participate in mathematical problem solving is vital for encouraging students to have a chance to create and develop metacognitive strategies; therefore, it requires conditions and contextual factors related to the classroom and learning and teaching activity design which is based on thorough and careful planning including consideration of the teacher's and students' roles with an emphasis on practice guidelines leading to students' participation by “creating knowledge from learning how to solve problems by themselves". The teacher and students should consider these issues and work together to find practice guidelines for creating good classroom contexts, leading to the development of students' metacognitive strategies as an outcome.

Another aspect of Silver's research (1985) suggests that study concerning metacognition is an important issue and should be considered for further research on mathematical problem solving, especially the study on development of a person or a group of people in age ranges related to ones' ability to solve problems, which is a necessity. According to Silver's belief, studying that aspect is fundamental for knowledge seeking, used by 
researchers for understanding mathematical learning and teaching processes. In addition, the process of considering and determining research issues on that aspect is important as a driving force in the future problem solving theory. Moreover, Lester's study (1994) stated that there are 3 study findings acceptable concerning successful influences of metacognition in problem solving. The first finding, effective activities related to metacognition during problem solving, was that students needed not only to know something and when to monitor it but also to know how to monitor it, meaning that teaching students how to monitor their behavior was considered a difficult task. The second finding was that teaching students to realize what happened as they knew and monitored their performance in better problem solving should occur in the context of learning mathematical concepts and techniques, in particular for learning and teaching in general which could take place but less efficiently. The third finding was that complete metacognition development was difficult and sometimes required stopping inappropriate behavior development from previous experiences (Schoenfeld, 1992). Those issues indicate that study on metacognition contains an important aspect that should be examined and explained more in research, especially finding ways of learning and teaching management as well as elements and conditions of development of students' metacognitive strategies leading to efficiency.

The study was conducted at a school which has participated in the Teacher Professional Development Project with innovations in lesson study and open approach since 2006. The following 3 steps instituted as a method of lesson study in the process underlying collaboration among a teacher or a student as a teaching practitioner, an observing teacher, a school coordinator, and the researcher were illustrated as in Figure 1: 1) participation in learning management planning; 2) collaborative class observation; and 3) mutual result reflection on teaching practice.

An issue of importance mentioned above has brought about a research question concerning how practice guidelines on classroom action affecting development of students' metacognitive strategies in the open approach-based mathematics classroom were represented in three issues: the framework for learning and teaching activities in the class, the teacher's role, and the students' role.

\section{Objective}

The research aimed at studying practice guidelines in the

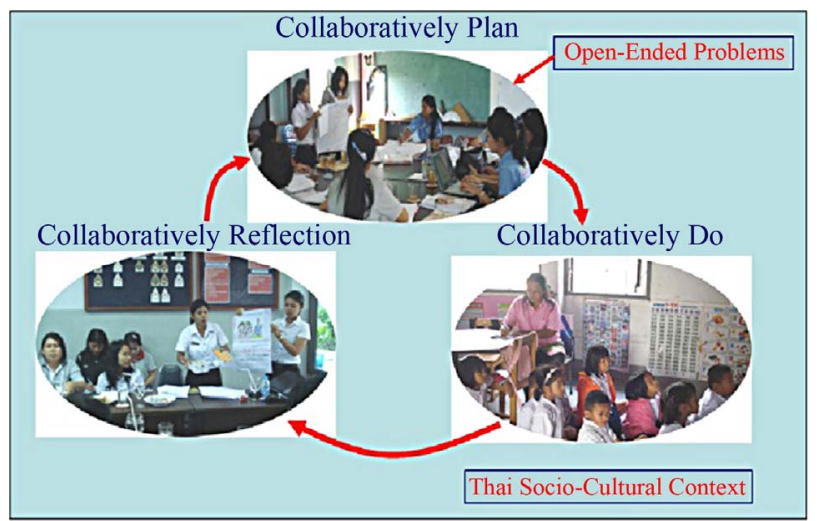

Figure 1.

Lesson study cycle (Inprasitha, 2004). classroom as a contextual factor affecting the development of students' metacognitive strategies in the mathematics classroom using the open approach on 3 issues: the framework for learning and teaching activities in the class, the teacher's role, and the students' role.

\section{Method}

As for the research methodology, ethnographic research was conducted, and Begle's conceptual framework (1969), which focused on observing the nature of occurrences, was employed. The researcher had conducted participatory classroom observations from the academic years 2008 to 2010. Data were collected in the academic year of 2010 in order to analyze findings. The target groups consisted of one teacher who was a student as a mathematics teaching practitioner at a school from Khon Kaen University and four elementary school students in grade 1 aged 6 to 7 years (1 male and 3 females) from Koo Kham Pittayasan School. Data were collected from the following 3 learning units totaling 6 study periods: addition (2), subtraction (2), and addition or subtraction? Qualitative data analysis procedures were based on analyzing videos, protocols, students' written work, and time units for dealing with activities and narrative description. The analysis on the teacher's teaching behavior and students' problem solving behavior was based on the following 4 open approach-based teaching steps (Inprasitha, 2010).

1) Posing open-ended problems;

2) Students' self learning;

3) Whole class discussion and comparison;

4) Summarization through connecting students' mathematical ideas emerging in the classroom.

The research tools included a learning management plan developed from a lesson study process which comprised 6 study periods one of which totaled 60 minutes, field notes, and videos.

\section{Results}

Practice guidelines as a contextual factor affecting the development of students' metacognitive strategies in the open approach-based mathematics classroom were addressed on 3 criteria: the framework for learning and teaching activities in the class, the teacher's role, and the students' role. Based on the use of analytical description, the obtained results are demonstrated hereinafter.

\section{Framework for Learning and Teaching Activities in the Class}

1) Learning management planning in connection with learning unit structures

The lesson study team began the learning management planning by working together to design learning unit structures by determining purposes and a number of study periods for each learning unit. What was taken into account was what students could learn after they finished each learning unit. To study that issue, the lesson study team used mathematics textbooks attached to the Teacher Professional Development Project with the innovation of lesson study and open approach as a main document for reference and as a guideline for design. Subsequently, towards the planning of learning management for each study period, the team determined purposes of learning con- 


\section{A. SURIYON ET AL.}

nected with previously planned purposes of learning. Based on field notes gathered from mutual learning management planning, the learning and teaching planning structure was designed by the Center for Research in Mathematics Education, Khon Kaen University. The structure of learning and teaching activities with an emphasis on 4 open approach-based teaching steps and the concept of students' approach to solving problems were used for the planning of learning management for each study period. The results of the procedure showed that the learning unit structure had impacts on students' thinking structures. For example, in the learning unit on addition (2), most of the ideas that students applied to problem solving were the product of accumulative recording of previous learning experiences, in- dicative that the learning unit structure designed for helping students apply what they learned to further utilization was indeed implemented.

2) Structure of learning and teaching activities for each period, as a part of time taken from arranging activities

With regard to learning and teaching activities emerging in each study period, the teacher planned activities emphasizing 4 open approach-based steps. Table 1 shows the time used for managing activities for each step.

From the data shown in Table 1, the researcher calculated the average time used for each open approach-based teaching step, time elapsed from actual classroom action is shown in Table 2.

Table 1.

Time used for instructional activity management for each open approach-based teaching step.

\begin{tabular}{|c|c|c|c|c|c|}
\hline $\begin{array}{c}\text { Learning unit } \\
\text { (Gakkoh Tosho, 1999) }\end{array}$ & Period & Activity name & $\begin{array}{c}\text { Open approach-based } \\
\text { teaching step }\end{array}$ & Start time-end time (hour) & $\begin{array}{l}\text { Total time taken } \\
\text { (hour) }\end{array}$ \\
\hline \multirow{13}{*}{$\begin{array}{l}\text { Learning unit 8: } \\
\text { addition (2) }\end{array}$} & \multirow{5}{*}{$1 / 12$} & \multirow{5}{*}{ Children playing in sandboxes and on slides } & Step 1 & 00:00:00 - 00:18:00 & 00:18:00 \\
\hline & & & Step 2 & 00:18:01 - 00:42:47 & $00: 24: 47$ \\
\hline & & & Step 3 & 00:42:48 - 00:59:07 & 00:16:20 \\
\hline & & & Step 4 & 00:59:08 - 01:18:30 & 00:19:23 \\
\hline & & & Total time & 00:00:00 - 01:18:30 & 01:18:30 \\
\hline & \multirow{4}{*}{$3 / 12$} & \multirow{4}{*}{ Buying eggs to make omelets } & Step 2 & 00:07:50 - 00:33:58 & 00:26:08 \\
\hline & & & Step 3 & $00: 33: 58$ - 00:49:16 & $00: 15: 18$ \\
\hline & & & Step 4 & $00: 49: 16-00: 52: 58$ & 00:03:42 \\
\hline & & & Total time & 00:02:10 - 00:52:58 & 00:50:48 \\
\hline & \multirow{4}{*}{$6 / 12$} & \multirow{4}{*}{ Delighted Natalie } & Step 1 & 00:02:15 - 00:06:15 & 00:04:00 \\
\hline & & & Step 2 & 00:06:15 - 00:31:12 & $00: 24: 57$ \\
\hline & & & Step 4 & 00:56:23 - 01:08:58 & 00:12:35 \\
\hline & & & Total time & 00:02:15 - 01:08:58 & 01:06:43 \\
\hline \multirow{10}{*}{$\begin{array}{l}\text { Learning unit 9: } \\
\text { subtraction (2) }\end{array}$} & \multirow{6}{*}{$11 / 12$} & \multirow{4}{*}{ Review exercises } & Step 1 & 00:00:00 - 00:01:50 & 00:01:50 \\
\hline & & & Step 2 & 00:01:50 - 00:46:03 & $00: 44: 13$ \\
\hline & & & Step 3 & $00: 46: 03-00: 58: 35$ & $00: 12: 32$ \\
\hline & & & Step 4 & 00:58:35 - 0:01:07:08 & 00:08:33 \\
\hline & & \multirow{6}{*}{ A cockerel and his chicks } & Total time & 00:00:00 - 0:01:07:08 & 01:07:08 \\
\hline & & & Step 1 & $00: 14: 45-00: 15: 52$ & 00:01:07 \\
\hline & \multirow{4}{*}{$11 / 13$} & & Step 2 & 00:15:52 - 00:40:30 & $00: 24: 38$ \\
\hline & & & Step 3 & 00:40:30 - 01:04:25 & $00: 23: 55$ \\
\hline & & & Step 4 & 01:04:25 - 01:07:56 & 00:03:31 \\
\hline & & & Total time & $00: 14: 45-01: 07: 56$ & 00:53:11 \\
\hline \multirow{3}{*}{$\begin{array}{l}\text { Learning unit 10: } \\
\text { addition or subtraction? }\end{array}$} & \multirow{3}{*}{$5 / 5$} & \multirow{3}{*}{ Coming train } & Step 1 & 00:00:00 - 00:05:15 & 00:05:15 \\
\hline & & & Step 4 & $00: 57: 50$ - 01:14:11 & $00: 16: 21$ \\
\hline & & & Total time & 00:00:00 - 01:14:11 & 01:14:11 \\
\hline
\end{tabular}

Table 2.

Average time used in each open approach-based teaching step.

\begin{tabular}{ccc}
\hline Step & Sequence of teaching & Average time (hour) \\
\hline 1 & Posing open-ended problems & $00: 05: 59$ \\
2 & Students' self learning & $00: 29: 37$ \\
3 & Whole class discussion and comparison & $00: 18: 49$ \\
4 & Summarization through connecting students' mathematical ideas emerging in the classroom & $00: 10: 41$ \\
& Total time & $01: 05: 05$ \\
\hline
\end{tabular}

Note: The total number of study periods was 6 . 
The data analysis results from Table 2 show the average time used in each teaching step from the total number of study periods, 6 . The study results also show that the time used differs in each step, and there is an accounting provided of the time used from most to least. The first order was the second step taking approximately 29 minutes, 37 seconds. The third step taking 18 minutes, 49 seconds was ranked second. The fourth step took 10 minutes, 41 seconds, and the first took the least time, 5 minutes, 59 seconds. The total time used towards activity management was 1 hour, 5 minutes, 5 seconds per study period.

\section{3) Structure of students' performing activities}

Students participated in performing activities in 4 open approach-based teaching steps with different aims depending on the intended purposes of learning for each study period, mathematical contents, as well as the aim of monitoring students' ideas. The structure of students performing activities is characterized by 3 kinds of activities.

Individual activity is defined as an activity in which a teacher requires each student to demonstrate ideas and methods of problem solving by writing ideas from documents or writing ideas on a piece of paper and then presenting these ideas (one person per one piece of work). This activity emphasizes completing exercises at the end of a study period for each learning unit including activities in the learning unit 8 on addition (2) in the study period $11 / 12$ and review exercises.

Sub-group activity is an activity in which the teacher requests a student who is a member of his or her group to show ideas and ways of problem solving by writing ideas from documents or writing ideas on a piece of paper and then presenting those ideas (one group per 1-2 pieces of work). The number of members of each group was between 3 and 5 people. Students determined tasks for each member, and members of each group studied together and presented their work in front of the class. This kind of activity mainly emphasizes solving problems together. The first step consisted of presenting open-ended situation problems which could be taken from the activities in the learning unit 8 on addition (2), in period 1/12, Children Playing in Sandboxes and on Slides, in period 3/12, Buying Eggs to Make Omelets, in period 6/12, Delighted Natalie including activities in the learning unit 9 on subtraction (2), in period $11 / 13$, and the learning unit 9 on addition or subtraction, in period 5/5, Coming Train.

Whole class activity is an activity in which the teacher requests a student who is a member of the class to show ideas and ways of problem solving by writing ideas from documents or writing ideas on a piece of paper and then presenting ideas (one group per one piece of work or one group per 1-2 pieces of work). Individual activities or group activities may be used for whole class activities. Whole class activities in the research were characterized by competition games included in activities in the learning unit 8 on addition (2), in period 9/12, Let's Arrange Cards, in period 10/12, Let's Play Cards on Addition, and in period 12/12, Wheel Ring of Addition.

\section{4) Structure of student work presentation}

The structure of the student work presentation in the mathematic classroom using the open approach is described as follows.

a) The teacher was tasked to assign a group to give a presentation with instructions provided for putting the presentations in correct order based on incorrect ideas, uncomplicated ones, or the ones that most students could perform. First, the teacher presented the aforementioned ideas in order to illustrate the required tasks. Next, the teacher chose complicated ideas and the ideas that a small number of students could perform, which were the concepts that reflected advances in achievement according to purposes of each study period before entering the next step.

b) After a person on behalf of his group finished giving a presentation in front of the class, the audience asked questions by raising their hands to show their intention to set problems or ask questions.

c) When the person who gave a presentation got a question, he then answered the question, or the teacher prompted members in each group to help each other determine answers or participate in showing opinions.

d) When there was no question, the person who gave a presentation went back to his group. For group tasks posted on the black board, the person who gave a presentation could not take his group task back to his group because the specific task would then be used for comparing ideas from each group and for drawing conclusions to connect with ideas emerging in the next step.

\section{The Roles of Teacher in the Classroom}

The data analysis findings on the teacher's teaching behavior in the open approach-based mathematics classroom illustrated that in each teaching step, the teacher played an important role in the development of students' metacognitive strategies. Specifics for each of the teaching steps are detailed below.

Step 1 Posing open-ended problems: In this step, the teacher was tasked as "a motivator" in order to allow students the opportunity to participate in problem solving and better understand problems with an emphasis on students' interpretations of pictures or media used for presenting problem situations and the teacher's use of motivating questions such as the following conversation in the learning unit 8, in period 1/12, Buying Eggs to Make Omelets.

Teacher: "Well, look at this (posting the picture on the blackboard). What is it?”

Students: Saying “Wow!” (all together, the whole class)

Student A: "It is a picture of people playing on swings"

Student B: “and playing in the sand”

(The student describes the picture as he sees it on the board).

Moreover, the teacher encouraged students to take on more participation as a demonstrator or as a person who took the initiative or used role playing by calling on students in the class to act out the proposed situation.

Step 2 Students' self learning: In this step, the teacher was tasked as "a supporter and a facilitator" with the intent to help students more effectively and to realize her role of getting involved in students' problem solving. The aim of the second step was that students learned to solve problems by themselves; that is to say, the teacher could help students when they needed help or asked clarification questions which could arise after they encountered difficulties in problem solving. The teacher could give advice to students so that they could solve problems and overcome difficulties in problem solving by themselves. However, a teacher's role did not include providing ways of solving problems or giving answers to students. As for the teacher's 
role of motivating students to continually apply themselves and progress in problem solving, the teacher encouraged students to this end by prompting them during problem solving, which was evidenced by the teacher's elicitations as provided below from unit 8, in period 1/12, Buying Eggs to Make Omelets, "Try to think in different ways".

Step 3 Whole class discussion and comparison: In this step, students monitored one another and reflected on problem solving, and the teacher had an important role as an initiator of classroom discussion by proposing issues for whole class consideration. In other words, the teacher played the role of "a coordinator of understanding" by creating an atmosphere of discussion in order that students could consider the opinions and suggestions of their classmates.

Step 4 Summarization through connecting students' mathematical ideas emerging in the classroom: The teacher was tasked in this step as “a connector” to summarize students' ideas by connecting students' ideas in 2 ways.

1) Drawing conclusions through synthesizing student ideas: The teacher was tasked to propose a problem to students to in order to ascertain the spectrum of ideas and approaches to meeting task objectives during the whole class discussion stage so that students could evaluate ideas and ways which helped them to solve problems effectively; that is, solving problems easily, quickly, and correctly. Based on the analysis results, students came to the conclusion that producing 10 was a factor that motivated them solve problems effectively, and other concepts such as counting, adding, and counting one for each item also helped them solve problems but were quite slow ways sometimes resulting in miscounting.

2) Drawing conclusions through synthesizing ideas that students applied to problem solving and initial situations or problems: In this step, the teacher was tasked with preparing media and organizing media systems. Tools used in each study period from beginning of activities included pictures and instructions used for initial situations, work showing students' ideas, and media. These tools were then used to check students' understanding of whether or not the ideas used in problem solving were consistent and rational with initial problems.

\section{The Roles of Student in the Classroom}

The analysis results on students' problem solving behavior in the open approach-based mathematics classroom illustrated that in each teaching step, a student was tasked to know how to solve problems himself, which could lead to development of metacognitive strategies. Student tasks for each of the teaching steps are detailed below.

Step 1 Posing open-ended problems: In this step, students were tasked as "participants trying to understand situation problems" by making observations of what they saw from pictures or media used for presenting problem situations including the teacher's answering of questions. Examples of students' answers from observations and the teacher's answering of questions are in the following conversation in the learning unit 8 , in period 1/12, Buying Eggs to Make Omelets.

Teacher: "Well, look at this (posting the picture on the blackboard). What is it?”

Students: Saying “Wow!” (all together, the whole class)

Student A: "It is a picture of people playing on swings"
Student B: "and playing in the sand"

(The student describes the picture as he sees it on the board).

Moreover, students were tasked as "demonstrators" or "experimenters" relevant to media that the teacher presented or that of a role of "an actor in role playing" in the situation problem presented by the teacher.

Step 2 Students' self learning: In this step, students were tasked as "problem solvers" with regard to learning how to solve problem themselves; that is, they had to encounter difficulties in self-problem solving, be cognizant of ideas or ways that they previously learned and used as problem solving tools. Students' roles while problem solving in sub-groups were that of "idea recorders", "observers of situation problems", and "examiners". For these roles, any student who was influential in his group often had the privilege to choose roles before other members in the group. Mostly, he was a student who demonstrated greater abilities than others. Furthermore, when the teacher prompted students during problem solving by saying, for example, "Try to think in different ways", thereafter students usually tried to find various other ways to solve problems.

Step 3 Whole class discussion and comparison: In this step, students were tasked as "persons who give presentations" and "an audience of a presentation of work concerning the collaboration of students in problem solving activities. Students in the whole class monitored one another and reflected on the problem solving process including discussion with members in the class.

Step 4 Summarization through connecting students' mathematical ideas emerging in the classroom: In this step, students were tasked as "evaluators" as they were required to answer the teacher's questions in order to compare the effectiveness of ideas and approaches to presentation creation during the whole class discussion stage, including examining whether or not and how ideas used for problem solving were consistent and rational with initial expectations.

\section{Discussion and Conclusion}

Contextual factors related to classroom action affecting the development of students' metacognitive strategies in the open approach-based mathematics classroom are detailed in the following three issues.

1) Structure of learning and teaching activities in the class

As for the structure of learning and teaching activities in the class, in the study, the research considered the following 4 issues: learning management planning related to the following structures: learning units, periodic instructional activities considered from time used for arranging learning and teaching activities, students' performing activities, and students' work presentation. The study findings indicated the importance of each issue concerning emerging structures of instructional activities, especially activities underlining problem solving processes which could prompt students to develop metacognitive strategies as well as results obtained from a time study used in arranging activities, showing that students spent the most time engaged in the second step of self-learning. These results confirmed students' ability to perform more tasks than simply finding answers only, which was considered evidence proving that students had indeed furthered the development of their metacognitive strategies. 
2) The roles of teacher in the classroom

As for teacher's roles with regard to helping students to develop metacognitive strategies, what teachers should be most cognizant of was their role in getting involved in problem solving to help students at the right time so that students could then best help themselves. The teacher was tasked as the person responsible for determining the directions of activities emerging in the class. In other words, students could be empowered toward self-learning in the future. The fundamental practice guideline was that the teacher had to understand and know when to get involved in students' problem solving at the appropriate time, corresponding to Polya (1957) in which the teacher had to rely on experiences in classroom observations until she could interpret students' thinking processes in any activity as well as surrounding factors emerging in the classroom, for example, situation problems that the teacher presented to students, instructions, and instructional media used in activities. When students could solve problems by themselves, the outcome was that a variety of ideas in problem solving emerged.

3) The roles of students in the classroom

For student's roles in the mathematics classroom using the open approach, students were responsible for carrying out various important tasks in the class. Receiving emerging different roles while performing instructional activities helped students to evolve their roles differently. The outcome was that students had a chance to develop learning skills and process extensively: problem solving, mathematical communication, expressions showing thinking, linking, and reasoning. In particular, in the aspect of problem solving, students could learn from their actions, leading to accumulative recording of "resources" gained from experiences according to roles that students received as in Schoenfeld (1985) suggesting that these existent resources are fundamental elements related to success and failure in problem solving.

\section{Acknowledgements}

This research was supported by the Higher Education Research Promotion and National Research University Project of Thailand, Office of the Higher Education Commission, through the Cluster of Research to Enhance the Quality of Basic Educa- tion. This research was partially supported by the Center for Research in Mathematics Education, Thailand.

\section{REFERENCES}

Begle, E. G. (1969). The role of research in the improvement of mathematics education. Educational Studies in Mathematics, 2, 232-244. http://dx.doi.org/10.1007/BF00303460

Flavell, J. H. (1976). Metacognitive aspects of problem solving. In L. B. Resnick (Ed.), The nature of intelligence (pp. 231-236). Hillsdale, NJ: Erlbaum.

Gakkoh Tosho Co., LTD (1999). Study with your friends MATHEMATICS for elementary school 1st grade Gakkoh Tosho. Tokyo: Gakkotosho Co., LTD.

Inprasitha, M. (2004). Teaching by open-approach method in Japanese Mathematics Classroom. KKU Journal of Mathematics Education, 1, $1-17$.

Inprasitha, M. (2010). One feature of adaptive lesson study in Thailand-Designing learning unit. Proceeding of the 45th Korean $\mathrm{Na}$ tional Meeting of Mathematics Education (pp. 193-206). Gyeongju: Dongkook University.

Lesh, R. (1982). Metacognition in mathematical problem solving. Unpublished manuscript.

Lester, F. K. (1994). Musings about mathematical problem-solving research: 1970-1994. Journal for Research in Mathematics Education, 25, 660-675. http://dx.doi.org/10.2307/749578

Polya, G. (1957). How to solve it (2nd ed.). Princeton, NJ: Princeton University Press.

Schoenfeld, A. H. (1982). Some thoughts on problem solving research and mathematics education (pp. 27-37). Mathematical problem solving: Issue in research. Philadelphia: Franklin Institute Press.

Schoenfeld, A. H. (1985). Mathematical problem solving. New York: Academic Press.

Schoenfeld, A. H. (1992). Learning to think mathematically: Problem solving, metacognition, and sense making in mathematics. In D. A. Grows (Ed.), Handbook of research on mathematics teaching and learning (pp. 334-370). New York: Macmillan.

Silver, E. A. (1982). Thinking about problem solving: Toward an understanding of metacognitive aspects of mathematical problem solving. Paper Prepared for the Conference on Thinking, Fiji.

Silver, E. A. (1985). Research on teaching mathematical problem solving: Some underrepresented themes and needed directions. Teaching and learning mathematical problem solving: Multiple research perspectives. Hillsdale: Lawrence Erlbaum Associates. 